\title{
MENJADI KORBAN YANG DISALAHKAN DALAM NOVEL PERMATA DALAM LUMPUR KARYA SATRIA NOVA DAN NUR HUDA
}

\author{
Eva Fauziyanti
}

\begin{abstract}
Surabaya is the second largest city after Jakarta, as the second largest city, Surabaya is a densely populated area, can be found various kinds of informal economic activities that have existed since colonial times, ranging from street vendors to prostitution. Dolly is an exclusive area located in Surabaya. This region is tehe largest prostitution in Indonesia, even beating in Southeast Asia. Research on the Permata In the Mud novel by Satria Nova and Nur Huda focuses on the representation of the meaning of violence on prostitutes, to lead us to a thought that criticizes every form of violence against women. This research method is a qualitative analysis, using Ferdinand de Saussure's semiotic analysis, which looks at markers and markers. The data used in the form of texts that describe violence against prostitutes in the novel Permata Dalam Lumpur, which is read repeatedly. The results found several meanings of violence on prostitutes obtained from several chapters. The results showed that the Permata novel in the mud contained the meaning of violence on prostitutes. In this study also found that one commercial sex worker is a victim of a pimp.
\end{abstract}

Keywords: Ferdinand de Saussure; novel; semiotics; violence against prostitutes

\begin{abstract}
Abstrak
Surabaya merupakan kota terbesar kedua setelah Jakarta, sebagai kota terbesar kedua, Surabaya merupakan kawasan padat penduduk, dapat ditemui berbagai macam aktivitas ekonomi informal yang sudah ada sejak zaman kolonial, mulai dari pedangan kaki lima hingga prostitusi. Dolly merupakan kawasan ekslusif yang terletak di Surabaya. Kawasan ini merupakan prostitusi terbesar di Indonesia, bahkan mengalahkan di Asia Tenggara. Penelitian pada Novel Permata Dalam Lumpur karya Satria Nova dan Nur Huda memfokuskan pada representasi makna kekerasan pada pelacur, untuk mengantarkan kita pada sebuah pemikiran yang mengkritisi setiap bentuk kekerasan terhadap kaum perempuan. Tujuan dari penelitian ini adalah untuk melihat kekerasan pada korban prostitusi yang ditulis oleh Satria Nova dan Nur huda. Metode penelitian ini adalah analisa kualitatif, dengan menggunakan analisis semiotika Ferdinand de Saussure, yang melihat pada petanda dan penanda. Hasil penelitian menunjukkan bahwa novel Permata dalam lumpur mengandung makna kekerasan pada pelacur. Dalam penelitian ini juga ditemukan bahwa satu pekerja seks komersial adalah korban mucikari.
\end{abstract}

Kata kunci: Ferdinand de Saussure; kekerasan pada pelacur; novel; semiotika, ,

Menjadi Korban Yang Disalahkan Dalam Novel Permata Dalam

Lumpur Karya Satria Nova Dan Nur Huda

Eva Fauziyanti 


\title{
PENDAHULUAN
}

Perekonomian di Indonesia yang semakin buruk mengakibatkan angka pengangguran semakin meningkat, yang akhirnya meningkatnya kemiskinan di masyarakat. Hal ini di perparah dengan angka kelahiran yang setiap tahunnya begitu cepat sehingga populasi manusia yang berada di Indonesia semakin lama membludak dan pada akhirnya mengakibatkan persaingan hidup yang sangat komperatif di Indonesia.

Berdasarkan data dari Badan Pusat Statistik (BPS) jumlah penduduk miskin di Indonesia pada periode September 2013-Maret 2014 jumlah penduduk miskin daerah perkotaan turun sebanyak 0,17 juta, dari 10,68 juta pada September 2013 menjadi 10,51 juta pada Maret 2014. Sementara itu, di daerah pedesaan turun sebanyak 0,15 juta orang dari 17,92 orang pada September 2013 menjadi 17,77 juta pada Maret 2014. Namun pada tahun 2015 angka kemiskinan meningkat mencapai 28,59 juta orang (11,22 persen), bertambah sebesar 0,86 juta (https://www.merdeka.com/uang/data-kemiskinan-sejak-era-jokowi-mulai-20142018-naik-atau-turun.html/ akses 24 Oktober 2019,pukul 20:30 WIB).

Tercatatan angka kemiskinan terbesar berada pada pulau jawa. Tercatatan ada tiga provinsi yang memiliki angka kemiskinan terbanyak, yaitu Jawa Timur dengan jumlah penduduk miskin 4,11 juta jiwa, Jawa Tengah 3,74 juta jiwa, dan Jawa Barat 3,4 juta jiwa. Secara regional, penduduk miskin di Pulau Jawa mencapai 12,74 juta jiwa atau separuh total penduduk miskin di tanah air (https://databoks.katadata.co.id/datapublish/2019/07/31/inilah-sebaran-pendudukmiskin-di-indonesia-2019/ akses 24 Oktober 2019 pukul 21:00 WIB)

Salah satu faktor penyebab angka kemiskinan adalah kurangnya lowongan pekerjaan sesuai dengan kreafitas yang dimiliki setiap individu, sehingga hal ini mengakibatkan meningkatnya prostitusi yang berada di Indonesia khususnya di kota-kota besar. Dari hasil wawancara yang dilakukan di Surabaya terhadap sejumlah anak perempuan yang dilacurkan, diketahui bahwa anak-anak

\author{
Menjadi Korban Yang Disalahkan Dalam Novel Permata Dalam \\ Lumpur Karya Satria Nova Dan Nur Huda \\ Eva Fauziyanti
}


perempuan yang terjerumus dalam bisnis prostitusi biasanya dipaksa oleh tiga faktor utama. Pertama, terjadi desakan perekonomian, kemiskinan dan kurangnya akses ke pekerjaan. Kedua, menjadi korban penipuan, korban dating rape, akibat keluarga yang broken home, korban child abuse, adanya kekecewaan yang disebabkan karena love affair yang gagal, dan ketiga, sebagai gaya hidup (Bagong, 2014:69).

Dari ketiga faktor ini, Menurut Keith Hart prostitusi termasuk dalam jasa kegiatan perekonomian di sektor informal ilegal karena kegiatan tersebut bertentang dengan hukum (Odam, 2018:33). Prostitusi merupakan kekerasan pada perempuan dengan motif perekonomian yang dapat merugikan kaum perempuan.

Prostitusi merupakan fenomena yang sudah ada sejak lama di dunia, tidak terkecuali di Indonesia. Prostitusi di Indonesia bermula sejak zaman kerejaankerajaan jawa yang menggunakan wanita sebagai bagian dari komoditas sistem feodal. Fenomena prostitusi hingga saat ini masih menjadi masalah yang belum terselesaikan (Kartini, 2005:266).

Keberadaan pelacur di Indonesia meresahkan kondisi lingkungan keluarga maupun masyarakat, karena prostitusi dalam kehidupan masyarakat dapat mengganggu ketertiban umum dan merusak generasi muda sebagai penerus bangsa. Salah satu faktor yang mendukung meningkatnya pelacur adalah lahanlahan atau tempat yang diorganisir secara rapi menampung para pelacur.

Hampir di setiap kota di Indoseia memiliki lahan untuk menampungan pelacur, yang biasa di sebut sebagai rumah bordil atau lebih dikenal sebagai istilah lokalisasi. Dalam kamus besar Indonesia merupakan pembatasan pada suatu tempat atau lingkungan, tetapi dalam penerapan ini bersifat negatif, yang biasanya identik dengan tempat prostitusi atau komplek pelacur (pangkalan pelacur).

Sebagai pekerja seks Komersial, harus bisa menyembunyikan identitasnya dalam kesehariannya, agar interaksi yang terjadi antara masyarakat dengan

\section{Menjadi Korban Yang Disalahkan Dalam Novel Permata Dalam Lumpur Karya Satria Nova Dan Nur Huda \\ Eva Fauziyanti}


pekerja seks komersial menjadi lebih muda dan terhindar dari sigma yang negatif. Budaya dan paham yang berkembang dalam masyarakat menyangkut nilai dan norma sosial ataupun agama jelas menjadi pertimbangan penting dalam proses interaksi sosial pekerja seks.

Perasaan berdosa yang dialami para pekerja seks Komersial menjadi satu dominan penting dalam dinamika sosial terkait interaksi sosial dalam masyarakat. Karena perempuan pekerja seks komersial selalu diasosiakan dengan perbuatan yang "hina" dan akan mendapatkan ganjaran neraka diakhirat. Doktrin-doktrin agama dalam menepatkan posisi pekerja seks komersial, tetapi tidak jarang pekerja seks komersial dalam kesehariannya masih melaksanakan ibada sholat, serta kajian keagamaan,seperti yang berada di surabaya tutup selama bulan ramadhan. Fenomena tersebut tentunya menghasilkan banyak penafsiran ada yang mengatakan penyamaran, ada pula yang menganggap sebagai sesuatu yang biasa saja.

Surabaya dikenal sebagai kota terbesar kedua setalah Jakarta, dengan berbagai gemerlap kehidupan kota metropolita yang penuh warna. Tetapi kota ini menyimpan banyak misteri yang belum mencuat kepermukaan. Surabaya terdapat lokalisasi bagi para pekerja seks Komersial yang sangat terkenal yaitu kampung Dolly. Kawasan prostitusi ini merupakan kawasan terbesar di Asia Tenggara (Satria dan Nur, 2011:3).

Lokasi Dolly berada di kembang kuning. Kembang kuning ini merupakan tempat pemakaman terbesar yang ada disurabaya. Lokas ini berada diantara kawasan putat jaya dan pakis, hanya membutuhkan waktu sekitar 10 menit untuk bisa sampai pada tempat ini. Nama kembang kuning diambil dari tanaman yang berbunga warna kuing yang banyak tumbuh di daerah tersebut.

Tak berbeda jauh dengan makam-makam pada umumnya, yang membedakan ketika pada malam hari. Saat siang hari makam ini tampak begitu sepi, justru pada malam hari makam ini berubah menjadi ramai. Ada suasana yang

\footnotetext{
Menjadi Korban Yang Disalahkan Dalam Novel Permata Dalam

Lumpur Karya Satria Nova Dan Nur Huda

Eva Fauziyanti
} 
berbeda saat mengunjungi kawasan ini di malam hari. Terdapat lima warung yang berada disana, karena makam ini merupakan tempat mangkal PSK yang didominasi waria, meski ada juga perempuan tulen.

Daerah yang disebut Dolly bukanlah yang berada di kembang kuning, tetapi berada di kawasan kupang timur, jarak hingga daerah putat jaya. Membentang di sela-sela rumah penduduk yang berada di kawasan tersebut. Secara administratif terbagi dalam tiga wilayah, yaitu Blok A, B, dan C. Setiap blok mempunyai ciri khas dan keunikan masing-masing (Satria dan Nur, 2011:2122).

Kawasan ini layaknya perkantoran atau bisa di sebut seperti perusahan besar yang sukses dalam menjalankan bisnisnya. Manajemen yang rapi diterapkan disana, ini terlihat dari pembagian blok yang ada. Tarif di setiap blok di sesuaikan dengan tingkat kenyamanan,fasilitas yang di berikan dan servis yang memuaskan. Sehingga tidak menutup kemungkinan omzet dari bisni tersebut jumlahnya mencapai miliaran. Semakin memilih fasilitas yang bagus maka tarifnya semakin tinggi Satria dan Nur, 2011:26).

Ada hal yang unik dikawasan ini sebab para para pekerja seks Komersial menggunakan seragam untuk bisa dibedakan mana yang sudah profesional dan belum dalam melakukan aktivitasnya. selain itu terdapat bunyi bell sebanyak empat kali setiap harinya dan setiap bunyi bel mempunya arti masing-masing.

Novel yang berjumlah 207 ini menceritakan tentang kisah nyata, yang terjadi pada perempuan yang terlibat dalam prostitusi terbesar dan tertua di Indonesia yaitu Dolly. Kawasan kawasan kupang timur, jarak hingga daerah putat jaya, Surabaya, Jawa Timur. Dunia pelacur di Dolly di ceritakan secara jelas dalam Novel Permata Dalam Lumpur, maka penulis menggunakan analisi semiotika Ferdinand de Saussure untuk memaknai tanda, yang berupa teks-teks yang menggambarkan makna pelacur dalam alur cerita Permata Dalam Lumpur.

\footnotetext{
Menjadi Korban Yang Disalahkan Dalam Novel Permata Dalam

Lumpur Karya Satria Nova Dan Nur Huda

Eva Fauziyanti
} 


\section{HASIL DAN PEMBAHASAN}

\section{A. Pencipta Novel Permata Dalam Lumpur}

Novel yang berjudul Permata Dalam Lumpur ditulis oleh Satria Nova dan Nur Huda pada tahun 2011, menceritakan tentang kehidupan Dolly di Surabaya, yang berada di kawasan Jarak atau Putu Jaya. Dolly merupakan Kawasan prostitusi terbesar di Indonesia, bahkan di Asia Tenggara mengalahkan Phat Pong di Bangkok, Thailand dan geylang di Singapura. Daerah lokalisasi sudah lama dan mampu bertahan selama 2019.

Selain itu dalam novel ini juga menceritakan tentang kisah unik yang terjadi di Dolly, diantaranya kisah-kisah mereka yang terjebak dengan dunia hitam, hingga bagaimana kawasan ini menjadi sentral bisnis esek-esek yang omzetnya mencapai miliaran rupiah perhari. Namun dalam penelitian ini, peneliti hanya memfokuskan kepada kekerasan yang di alami oleh salah satu pekerja Seks Komersial yang dijebak untuk bekerja seperti ini.

Novel ini merupakan catatan perjalanan penulis yang cukup lama berinteraksi di kawasan Dolly. Novel ini berangkat dari kisah nyata tentang kehidupan dan interaksi yang berada di Dolly.

\section{B. Analisis Novel berjudul Permata dalam Lumpur}

Pada halaman 61, baris pertama

“Namaku Sri, tapi orang memanggilku Putri. Itu nama yang diberikan mami kepadaku agar mereka tidak mengejekku. Nama sri dinilai kuno atau rendahan sehingga aku harus mengganti namaku menjadi Putri”

Dari cerita diatas kita dapat memaknai bahwa, nama memiliki nilai jual yang tinggi. Nama yang kuno atau bisa dibilang nama kampung dianggap rendah oleh para penikmat pekerja seks komersial. Sehingga Sri harus mengganti namanya menjadi Putri agar Mucikari bisa menjual Sri kepada penikmati pekerja seks komersial dengan harga yang mahal.

Baris kedua, pada halaman 61 
“ Aku dilahirkan dan dibesarkan di pinggir kota, di kawasan kumuh. Tempat dimana pengemis,pemulung dan anak-anak jalanan tinggal bersama. Bahkan pendidikanku tak tuntas. Aku bekerja ini karena desakan ekonomi, ayah ku sudah lama tiada, adek sekolah dan ibu sakitsakitan”

Dalam baris kedua ini, penokoh menggambarkan tentang rumah halamannya, yang jauh dari kata mewah. Hal ini dapat di maknai bahwa kehidupan yang berada disana ialah "berkecukupan" dalam artian ekonomi kelas bawah, pendapatannya tidak bisa memenuhi semua kebutuhan primer. Bahkan mungkin uang yang didapatkan hanya untuk sekali makan saja, dan untuk besok harus mencari kembali.

Sehingga karena desakan ekonomi, kebutuhan yang harus dipenuhi, Sri terpaksa bekerja sebagai pekerja komersial, karena ia harus memenuhi kebutuhan keluarganya. Tidak hanya desakan ekonomi, tetapi faktor pendidikan.

Halaman 62, baris pertama

“ Tak usah membayangkan, karena kau pun tak pernah peduli selama ini. Derita kami tak pernah jadi deritamu”

Dalam halaman ini bermakna bahwa, rasa sosialisasi kurang di tingkatkan. Kita kurang peduli dengan lingkungan sekitar, karena kesibukan yang kita miliki rasa sosial sebagai masyarakat tidak ada lagi. Rasa saling tolong menolong tidak lagi menjadi semboyan..

Baris kedua, pada halaman 62

“ Setidaknya setiap hari aku harus melayani 3 lelaki hidung belang,

bahkan ketika ramai bisa 8 orang. Mami selalu memberiku pil setiap harinya, biar aku kuat katanya"

Dari penuturan diatas Sri menceritakan aktivitas yang ia lakukan. Para pekerja seks pada umumnya, harus melayani 3 sampai 8 orang dalam setiap malamnya, 
sehingga untuk bisa melayani 3-8 orang tersebut, mami atau Mucikari memberikan pil kuat. Hal ini terlihat kejam dan melanggar HAM seseorang. hanya untuk mendapatkan uang, Mucikari tidak memanusiakan manusia, sebab ia menjadikan Sri atau pekerja lainnya seperti robot yang harus melakukan perintahnya.

Baris ketiga, pada halaman 62

\section{“ Jiwaku terkoyak. Batinku tersiksa dan tubuhku dijaja”}

Kata "terkoyak" bukanlah arti yang sebenarnya, penokoh memberikan kata kiasaan dalam memahamkan pembaca, agar pembaca bisa mengerti atau ikut merasakan bagaimana penderitaan Sri selama ini. Kata "terkoyak" berasal dari kata dasar "koyak" yang berarti mencabik, merobek. Sehingga dapat dimaknai bahwa, jiwa Sri sudah lama tiada, ia hidup seperti orang meninggal, tidak berjiwa, karena jiwanya telah tercabik-cabik akan keadaan yang memaksa dirinya untuk melakukan hal yang tidak ia sukai selama ini.

Batin yang "tersika"memiliki kata dasar "siksa" yang berarti penderitaan (kesengsaraan), jika diartikan dengan penuturan Sri ialah batinnya menderita, karena ia harus berulang kali melayani para lelaki hidung belang, dan ia tak mampu untuk melawan semua keadaan, yang mungkin bagi dia.

Tubuhku "dijaja" kata jaja berarti menawarkan barang atau makanan. Hal ini diartikan bahwa tubuh Sri ditawarkan kepada setiap para lelaki hidung belang oleh mucikari, dalam artian tubuh Sri ibaratkan barang (barang dagangan) yang dibawa oleh Mucikari untuk ditawarkan, sehingga setelah barang itu laku sudah menjadi hak milik orang yang membeli.

Halaman 63, baris pertama

“ Dulu aku dijanjikan akan bekerja di restoran sebagai pelayan oleh wanita yang baru aku kenal. Ia menjanjikan upah 1,5 juta perbulan. Sehingga aku sangat tertarik dengan ajak itu. Dan tanpa fikir panjang aku menyetujuinya dan akhirnya aku berangkat ke Surabaya, setalah sampai disana ternyata aku 
harus bekerja seperti ini, ingin rasanya aku lari dan berontak tetapi aku tidak tau harus pergi kemana dan aku sudah berhutang kepadanya untuk membeli obat ibu”

Pada baris pertama, halaman 63 merupakan lanjutan cerita pada halaman sebelumnya. Dalam cerita ini Sri terlalu tergiur dengan gaji yang dijanjikan oleh orang yang baru ia kenal. Ceritat tentang asal usul kenapa Sri bisa menjadi pekerja seks komersial. Pengalaman ini men

gingatkan kita agar tidak mudah percaya dengan orang yang baru kita kenal. Bagaimana pun keadaan yang kita alami saat itu, kita harus dapat mencari informasi yang sebenarnya.

Kurangnya pemahaman serta pendidikan menjadi faktor utama yang dapat membuat kita percaya kepada orang yang kita baru kenal. Sehingga kita dapat terjebak dalam keputusan yang kita ambil sebelum kita memikirkannya terlebih dahulu dan mencari informasi. Dapat kita gambarkan sosok Sri yang polos, yang tidak tau bahwa dirinya akan dijual kepada Mucikari dan dia merupakan korban dari prostitusi.

Baris kedua, halaman 63

“ Dimatamu aku hanya wanita hina,yang pantas dirajam dan wanita yang pantas mendapat tiket ke neraka, bahkan terkadang para istri menghujat kami,padahal mereka sendiri yang datang,bukan kami yang meminta”

Doktrin-doktrin agama dan masyarakat sudah menjadi hal biasa bagi pekerja seks komersial, Meski norma agama sudah begitu tegas melarang praktik prostitusi tetapi tetap saja dilakukakan, hal utama ialah karena desakan ekonomi. Seperti yang dialami oleh Sri, sebenarnya dia adalah korban, yang tidak tau harus pergi kemana dan mengaduh kepada siapa. Selama ini masyarakat hanya menilai bahwa Sri adalah wanita hina dan pantes mendapatkan rajam. Sebenarnya dia sudah tidak tahan lagi bekerja sebagai seks komerisal, tetapi tak ada orang yang

Menjadi Korban Yang Disalahkan Dalam Novel Permata Dalam

Lumpur Karya Satria Nova Dan Nur Huda

Eva Fauziyanti 
mempedulikannya, sehingga mau tidak mau dia harus melanjutkan apa yang sudah di takdirkan dalam hidupnya.

Sri merupakan korban dari kebiadaban mucikari dan lelaki hidung belang. Ia hanya diperalat untuk melakukan perbuataan yang tidak dia senangi atau sukai. Tetapi tetap saja ia mendapatkan getah dari perbuatannya.

Baris ketiga halama 64

“ Aku tidak tega jika harus menyuapi keluargaku dengan barang

haram. Jika aku masuk neraka biarlah aku sendiri, aku tak ingin mengajak

ibu dan adik-adikku, karena mereka tidak tau tentang pekerjaan ku yang sebenarnya”

Dari akhir cerita ini, dapat kita maknai bahwa para pekerja seks komersial, tau tentang apa yang dilakukannya itu melanggar hukum Islam, tetapi lagi-lagi jika sudah berbicara tentang uang, selembar kertas yang sanggup membuat orang tunduk kepadanya. Kerana desakan ekonomi orang mampu melakukan hal apa saja, apalagi jika menyangkut kebutuhan seluruh anggota keluarga. Tidak ada orang yang mendengar jerit wanita yang sudah dianggap hina oleh masyarakat.

\section{SIMPULAN}

Dari hasil penelitian yang dilakukan, maka dapat ditarik kesimpulan bahwa novel yang berjudul Permata Dalam Lumpur memiliki penanda dan petanda yang memiliki relasi dan mendukung suatu petanda, yaitu kedzoliman, kekejian dan penindasan. Penulis menanamkan ideologi dengan membawa pembaca pada keadaan emosional, sehingga mengiring pembaca pada posisi prihatin terhadap keadaan yang menimpah tokoh utama yang mengalami berbagai perlakuan.

Terjunnya seorang perempuan ke dalam dunia prostitusi dilatarbelakangi oleh berbagai faktor, salah satu yang menjadi faktor utamanya ialah desakan ekonomi,sehingga seorang perempuan menerjuni dunia prostitusi untuk memenuhi kebutuhan pribadi dan keluarga, karena cara ini dianggap untuk bisa 
mempertahankan hidup. Seperti yang di ceritakan dalam novel Permata Dalam Lumpur, yang mengkisahkan seorang perempuan terjebak ke dunia prostitusi, selain faktor ekonomi, faktor pendidikan juga mempengaruhinya, sebab tokoh utama menceritakan bahwa ia bisa terjun ke dunia prostitusi karena ia terlalu percaya kepada orang yang baru ia kenal.

Bentuk prostitusi yang terjadi di Surabaya, dilakukan secara terang-terangan dan terorganisasi. Hal ini bertujuan untuk menerapkan disiplin dan kontrol terhadap aktivitas prostitusi. Namun tidak jarang, para pekerja seks komersial dalam cerita tersebut diberikan obat kuat untuk bisa melanyani 3 sampai 8 orang tamu yang datang, hal ini mentandakan.

\title{
DAFTAR PUSTAKA
}

\section{Buku}

Ahmad Saebani, Beni dan Afifuddin. 2009. Metodelogi Penelitian Kualitatif. Bandung: CV. Pustaka Setia.

Akhaamul Quran, 3/200

Baggue Jassin, Hans. 1965. Tifa Penyair dan Daerahnya. Jakarta: Gunung Agung.

de saussure, Ferdinan. 1990. Course in General Linguistics. Duckworth:London.

Huda Nur dan Satria Nova.2011. Permata Dalam Lumpur. Jakarta: PT Elex Media Komputindo.

Kartini. 2005. patologi sosia. Jakarta:Raja Grafindo Persada.

Kriyanto,Rachmat. 2009. Teknik Riset Komunikasi: Disertai Contoh Praktis Riset Media, Public Relations, Advertising,Komunikasi Organisasi,Komunikasi Pemasaran. Jakarta: Kencana.

Mursal. 1982. Sastra dan Tradisi Sub Kultur. Bandung: Angkasa.

Nurgiyanto,Burhan. 1995. Teori Pengkajian Fiksi. Yogyakarta: Gadjah Mada University Press.

Pawito. 2007. Penelitian Komunikasi Kualitatif. Yogyakarta:Lkis.

\author{
Menjadi Korban Yang Disalahkan Dalam Novel Permata Dalam \\ Lumpur Karya Satria Nova Dan Nur Huda \\ Eva Fauziyanti
}


Sobur, Alex .2006. Semiotika Komunikasi. Bandung:PT REMAJA ROSDAKARYA

Sobur, Alex. 2003. Psikologi Umum. Bandung:Pustaka Setia.

Strinati,Dominic. 2003. Populer Cultur: Pengantar Menuju Teori Budaya Populer. Yogyakarta:Benteng Budaya.

Suyanto, Bagong. 2014. Nak Perempuan Yang Dilacurkan: Alasan Menjadi Pelacur dan Mekanisme Adaptasi. Surabaya: Departemen sosiologi, Fak ilmu sosial dan ilmu politik, Universitas Airlangga.

Tafsir Kalam Al-Manna

Yamani, Mai. 2000. Feminisme dan Islam: Perspektif Hukum dan Sastra. Bandung: Penerbit Nuansa.

\section{Artikel Jurnal, Majalah, dan Surat Kabar}

Asdi Artosa, Odam. 2018. Pekerja Migran Dan Ekonomi Informal Ilegal (Prostitusi) Di Wilaya Pasar Kembang, Jurnal Pemikiran Sosiologi Volume 5 no 1

Maulana, Rizal dan Abdullah Muslich. 2013. Feminisme sebagai Diskursus Pandangan Hidup. Mahasiswa Semester VII Institut Studi Islam Darussalam, Jurnal KALIMAH, Vol. 11, No. 2.

Thamimi, Muhammad. 2016. Semiotik Dalam Novel Surat Kecil Untuk Tuhan Karya Agnes Davonar, Jurnal Pendidikan Bahasa, Vol. 5, No. 1.

\section{Website}

https://databoks.katadata.co.id/datapublish/2019/07/31/inilah-sebaran-pendudukmiskin-di-indonesia-2019 (24 Oktober 2019)

https://www.merdeka.com/uang/data-kemiskinan-sejak-era-jokowi-mulai-20142018-naik-atau-turun.html (24 Oktober 2019)

Menjadi Korban Yang Disalahkan Dalam Novel Permata Dalam

Lumpur Karya Satria Nova Dan Nur Huda

Eva Fauziyanti 